\title{
Effect of the annealing atmosphere on crystal phase and thermoelectric properties of copper sulfide
}

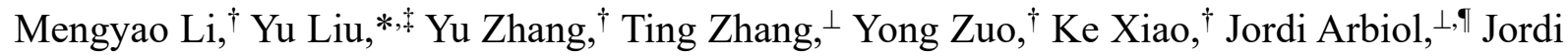
Llorca, ${ }^{\S}$ Maria Ibáñez, ${ }^{\ddagger}$ Junfeng Liu, ${ }^{*, *}$ Andreu Cabot*,†, $\uparrow$

${ }^{\dagger}$ Catalonia Energy Research Institute - IREC, Sant Adrià de Besòs, 08930 Barcelona, Spain.

${ }^{*}$ Institute of Science and Technology Austria (IST Austria), Am Campus 1, 3400, Klosterneuburg, Austria.

${ }^{\perp}$ Catalan Institute of Nanoscience and Nanotechnology (ICN2), CSIC and BIST, Campus UAB, Bellaterra, 08193 Barcelona, Catalonia, Spain.

"ICREA, Pg. Lluis Companys 23, 08010 Barcelona, Catalonia, Spain.

${ }^{\S}$ Institute of Energy Technologies, Department of Chemical Engineering and Barcelona Research Center in Multiscale Science and Engineering, Universitat Politècnica de Catalunya, EEBE, 08019 Barcelona, Spain

"Institute for Energy Research, School of Chemistry and Chemical Engineering, Jiangsu University, 212013 Zhenjiang, P.R. China

*E-mails: Y. Liu: yu.liu@ist.ac.at; J. Liu: jliu@ujs.edu.cn; A. Cabot: acabot@irec.cat 


\begin{abstract}
$\mathrm{Cu}_{2-\mathrm{x}} \mathrm{S}$ has become one of the most promising thermoelectric materials for application in the middle-high temperature range. Its advantages include the abundance, low cost and safety of its elements and a high performance at high temperature. However, stability issues limit its implementation in real devices, restraining their operation current and temperature, which calls for the optimization of the material performance in the middle temperature range. Here, we present a synthetic protocol for large scale production of covellite $\mathrm{CuS}$ nanoparticles at ambient temperature and atmosphere, and using water as solvent. The crystal phase and stoichiometry of the particles is afterward tuned through annealing at a moderate temperature under an inert or reducing atmosphere. While the annealing in an $\mathrm{Ar}$ atmosphere results in $\mathrm{Cu}_{1.8} \mathrm{~S}$ nanopowder with a rhombohedral crystal phase, the annealing in a reducing atmosphere leads to tetragonal $\mathrm{Cu} 1.96 \mathrm{~S}$. High temperature $\mathrm{x}$-ray diffraction analysis show the material annealed in argon to transform to the cubic phase at $c a .400 \mathrm{~K}$, while the material annealed in the presence of hydrogen undergoes two phase transitions, first to hexagonal and then to a cubic structure. The annealing atmosphere, temperature and air allows adjusting the density of copper vacancies and thus controlling the material transport properties. In this direction, the material annealed under Ar shows higher electrical conductivities but lower Seebeck coefficients than the material annealed in the presence of hydrogen. By optimizing the annealing time, $\mathrm{Cu}_{2-\mathrm{x}} \mathrm{S}$ with record figures of merit in the middle temperature range, up to 1.31 at $710 \mathrm{~K}$, are obtained. We finally demonstrate that this strategy, based on low cost solution synthesis process, is also suitable for the production of high performance $\mathrm{Cu}_{2-\mathrm{x}} \mathrm{S}$ layers using high throughput and cost effective printing technologies.
\end{abstract}




\section{INTRODUCTION}

Thermoelectric devices, able to convert ubiquitous temperature gradients into electricity, have countless potential applications, but their high manufacturing and materials costs hamper their cost-effectiveness and limit their widespread implementation. To overcome these drawbacks, thermoelectric devices must be manufactured using high throughput technologies and making use of materials based on low cost and abundant elements.

The thermoelectric properties of copper sulfides have been explored for well above a century. However, it was not until this last decade that copper sulfides raised especial attention not only because of the low-cost and abundance of the involved elements, but also because of their outstanding thermoelectric performance in the middle-high temperature range.

Copper chalcogenides and particularly copper sulfides are a fascinating family of materials with exceptional characteristics $^{1}$ : i) high element abundance, low cost and minor environmental and health impact; ii) enormous structural and compositional versatility; iii) low energy of formation of defects resulting in high defect densities; iv) chalcogen atoms forming regular lattices with $\mathrm{Cu}$ atoms occupying not well-defined interstitial sites; v) strong influence of $\mathrm{Cu}$ $3 \mathrm{~d}$ states in the chalcogenide electronic properties; vi) singular and highly tunable functional properties, including low direct band gaps, plasmonic properties, high charge carrier concentrations, high ionic conductivity, and low thermal conductivity.

Even the simplest binary $\mathrm{Cu}-\mathrm{S}$ system exhibits a particularly rich phase diagram with many possible stoichiometric compositions and crystallographic phases, some of them with quite complex atomic arrangements. The main crystal phases in the $\mathrm{Cu}-\mathrm{S}$ system at ambient temperature are the monoclinic chalcocite $\left(\mathrm{Cu}_{2.0-1.997} \mathrm{~S}\right)$, monoclinic djurleite $\left(\mathrm{Cu}_{1.97} \mathrm{~S}-\mathrm{Cu}{ }_{1.93} \mathrm{~S}\right)$, triclinic roxbyite $\left(\mathrm{Cu}_{58} \mathrm{~S}_{32}\right.$ or $\left.\mathrm{Cu}_{1.81} \mathrm{~S}\right)$, cubic digenite $\left(\mathrm{Cu}_{9} \mathrm{~S}_{5}\right.$ or $\left.\mathrm{Cu}_{1.8} \mathrm{~S}\right)$, orthorhombic anilite $\left(\mathrm{Cu}_{7} \mathrm{~S}_{4}\right.$ or $\left.\mathrm{Cu}_{1.75} \mathrm{~S}\right)$, and hexagonal covellite $(\mathrm{CuS})$. These crystal structures are based upon approximately hexagonal (djurlite, chalcocite, roxbyite and covellite) or cubic (anilite and digenite) close-packing of the sulfur atoms, with $\mathrm{Cu}$ atoms occupying various interstitial sites with different statistical probabilities that depend on temperature. ${ }^{2,3}$

Chalcocite $\mathrm{Cu}_{2} \mathrm{~S}$ displays a monoclinic $\mathrm{P} 21 / \mathrm{c}$ crystal structure. This is essentially a 
superstructure of a hexagonal lattice with slight distortions where the 36 crystallographically distinct Wyckoff sites are fully occupied with $12 \mathrm{~S}$ atoms and $24 \mathrm{Cu}$ atoms. ${ }^{3,4}$ Stoichiometric $\mathrm{Cu}_{2} \mathrm{~S}$ is considered to be intrinsically unstable at ambient conditions owing to a thermodynamic tendency towards loosing $\mathrm{Cu}$ through oxidation in the surface. ${ }^{5}$ Thus chalcocite nanoparticles degrade quickly into copper deficient $\mathrm{Cu}_{2-\mathrm{x}} \mathrm{S}$ phases, most notably djurleite $\mathrm{Cu}_{1.97} \mathrm{~S}$, which is considered the thermodynamically stable stoichiometry under ambient conditions.

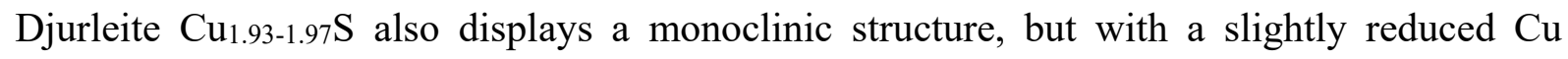
concentration. The unit cell content of djurleite corresponds to $\mathrm{Cu}_{62} \mathrm{~S}_{32}$ or $\mathrm{Cu}_{1.93} \mathrm{~S}$. If an extra $\mathrm{Cu}$ atom is added, the unit cell content becomes $\mathrm{Cu}_{63} \mathrm{~S}_{32}$ or $\mathrm{Cu}_{1.97} \mathrm{~S}$, thus explaining the lower

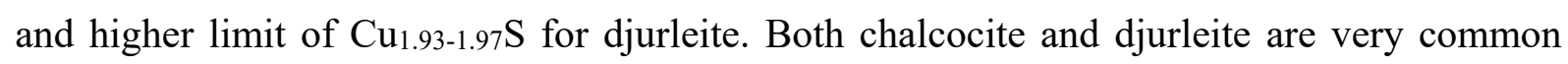
phases at ambient temperature and are often intermixed or intergrown. ${ }^{6}$

Roxbyite $\mathrm{Cu}_{58} \mathrm{~S}_{32}$ or $\mathrm{Cu}_{1.81} \mathrm{~S}$ is closely related to chalcocite and djurletite, but it has a triclinic structure consisting of a distorted hexagonal framework of $32 \mathrm{~S}$ atoms with 58 independent $\mathrm{Cu}$ atoms, all having triangular coordination. ${ }^{7}$ Roxbyite is uncommon in bulk, but can be readily synthesized in the form of nanocrystals. ${ }^{8}$

Digenite $\mathrm{Cu}_{1.8} \mathrm{~S}$ has a cubic, but still complex structure with space group Fd3m. Sulfur atoms form a fcc structure and the copper atoms are statistically distributed over several sites. It is sometimes referred to as $\mathrm{Cu}_{9} \mathrm{~S}_{5}$ but since $\mathrm{Cu}$ atoms are statistically distributed, the formula $\mathrm{Cu}_{1.8} \mathrm{~S}$ is preferred. ${ }^{9}$

Anitite $\mathrm{Cu}_{7} \mathrm{~S}_{4}$ or $\mathrm{Cu}_{1.75} \mathrm{~S}$ has an orthorhombic crystal phase, space group Pnma, in which the $\mathrm{S}$ atoms approximate an $\mathrm{fcc}$ arrangement and the $\mathrm{Cu}$ atoms are ordered in the interstices. ${ }^{10,11}$ Finally, covellite $\mathrm{CuS}$ has a peculiar layered structure for such a simple stoichiometry. It is also a hexagonal phase with alternating layers of $\mathrm{CuS}$ and $\mathrm{Cu}-\mathrm{S} 2-\mathrm{Cu} .^{12-14}$ This unusual structure is explained by the fact that it is more energetically favorable for the $\mathrm{S}$ atoms to covalently bond to each other than to bond with $\mathrm{Cu}$ atoms. ${ }^{12}$

The $\mathrm{Cu}-\mathrm{S}$ phase diagram is actually much more complex, with additional well-defined phases/minerals, including geerite $\left(\mathrm{Cu}_{1.6} \mathrm{~S}\right)$, spionkopite $\left(\mathrm{Cu}_{1.39} \mathrm{~S}\right)$ and yarrowite $\left(\mathrm{Cu}_{1.12} \mathrm{~S}\right)$. Furthermore, several metastable phases also exist and are commonly obtained at ambient temperature, such as a tetragonal $\mathrm{Cu}_{1.96} \mathrm{~S}$ phase ${ }^{6,15-17}$ and a rhombohedral $\mathrm{Cu}_{1.8} \mathrm{~S}$ structure. ${ }^{18,19}$ At relatively low temperatures, just above $70-100{ }^{\circ} \mathrm{C}$ depending on stoichiometry, $\mathrm{Cu}$ atoms 
become highly mobile, which makes it difficult to determine their exact positions. Thus only a statistical distribution of $\mathrm{Cu}$ atoms over the various Wyckoff positions in the lattice can be determined and the symmetry of the observed crystal structures increases. ${ }^{20,21}$ The ambient temperature monoclinic chalcocite phase, known as low chalcocite, transforms into a hexagonal phase known us high chalcocite at around $376 \mathrm{~K}$, and to a cubic phase at about $709 \mathrm{~K}$, known as cubic chalcocite. Monoclinic djurlite is stable up to about $363 \mathrm{~K}$. At this temperature it transforms into a combination of hexagonal chalcocite and cubic dijenite phases, with the hexagonal phase disappearing as increasing temperature. ${ }^{16}$ Dijenite undergoes complete phase transition into a higher symmetry cubic phase at even lower temperature, $346 \mathrm{~K} .^{9,18}$ The high temperature dijenite phase is known as high digenite, and it is identical to the cubic chalcocite. ${ }^{22}$ Above $710 \mathrm{~K}$ only high-digenite with $\mathrm{Cu}_{2} \mathrm{~S}$ composition or cubic chalcocite, in equilibrium with copper, can be obtained..$^{9,22}$ Anilite is also stable only to $345 \mathrm{~K},{ }^{22,23}$ transforming into the cubic high digenite phase at higher temperatures.

To make things even more complex, phase and stoichiometry do not always go together. For instance, hexagonal digenite has been reported especially in nanoparticle form, and a cubic high chalcocite has been also found. To minimize confusion, it is wise to associate the mineral names to the crystal phase regardless of the exact composition, thus hexagonal digenite should be better referred as a $\mathrm{Cu}$-deficient high chalcocite and the cubic high chalcocite as a $\mathrm{Cu}$-rich high digenite. $^{3}$

Phase transitions strongly depends on several parameters including the initial phase, pressure and composition. The lower the $\mathrm{Cu}$ content, the lower the transition temperature from monoclinic to hexagonal and cubic phase for instance. Besides, the phase transition temperature also strongly depends on the crystal domain size. A good example is observed for chalcocite $\mathrm{Cu}_{2} \mathrm{~S}$ nanocrystals, where the smaller the size, the smaller the transition temperature. ${ }^{24}$ Actually, small enough nanocrystals are reported to maintain the hexagonal high chalcocite phase even at ambient temperature. ${ }^{25}$ The atmosphere composition, and particularly the sulfur partial pressure is another parameter that strongly influences the phase transition. ${ }^{9}$

The electronic structure and functional properties of $\mathrm{Cu}_{2-\mathrm{x}} \mathrm{S}$ depend on both stoichiometry and crystal phase. In $\mathrm{Cu}$ chalcogenides, the top of the valence band has a strong contribution from the chalcogenide $\mathrm{p}$ orbitals and the bottom of the conduction band mainly has contributions 
from $\mathrm{Cu} 4 \mathrm{~s}$ and $4 \mathrm{p}$ orbitals. ${ }^{1,26} \mathrm{It}$ is assumed that each $\mathrm{Cu}$ atom contributes to bonding with one $4 \mathrm{~s}$ electron and each chalcogen atom contributes with six $\mathrm{p}$ electrons. In the fully stoichiometric $\mathrm{Cu}_{2} \mathrm{~S}$ material, the valence band is completely filled and the material would behave as an intrinsic semiconductor. However, when $\mathrm{Cu}$ vacancies are created, holes are generated in the top of the valence band. The Cu deficiency mainly affects the valency of the chalcogen, whereas the valency of $\mathrm{Cu}$ remains close to +1 in all phases and stoichiometries.

All $\mathrm{Cu}_{2-\mathrm{x}} \mathrm{S}$ exhibit p-type electronic character with a stoichiometry-dependent hole concentration that increases with the number of $\mathrm{Cu}$ vacancies (x). Besides, the type of sulfur arrangement in the crystal structure also plays an important role on the electronic transport properties of the material. ${ }^{27} \mathrm{On}$ the other hand, the $\mathrm{Cu}$ disorder provides the material not only with a high ionic conductivity but also an ultralow thermal conductivity. Overall, thermoelectric properties are very sensitive to the $\mathrm{Cu}$ deficiency, i.e. the $\mathrm{Cu}_{2-\mathrm{x}} \mathrm{S}$ phase and stoichiometry. Thus, phase tuning at the synthesis step or through post-synthesis treatments should be a very effective strategy to optimize thermoelectric properties of copper sulfide.

In the present work, we demonstrate a very simple and low-cost room temperature aqueous phase method for the large-scale preparation of copper sulfide. Additionally, we analyze the possibilities of crystallographic phase tuning of nanocrystalline $\mathrm{Cu}_{2-\mathrm{x}} \mathrm{S}$ by means of thermal annealing at moderate temperatures under inert or reducing gas atmospheres. Finally, we analyze the thermoelectric properties of the obtained compounds as a function of the annealing temperature and explain the obtained results taking into account the phase transitions undergone by the materials when heated. 


\section{EXPERIMENTAL}

Chemicals. Copper (II) nitrate trihydrate $\left(\mathrm{Cu}\left(\mathrm{NO}_{3}\right)_{2} \cdot 3 \mathrm{H}_{2} \mathrm{O}\right)$ and ammonium sulfide solution $\left(\left(\mathrm{NH}_{4}\right)_{2} \mathrm{~S} 20 \%\right.$ in $\left.\mathrm{H}_{2} \mathrm{O}\right)$ were purchased from Fisher. Chemicals were used as received without further purification.

Copper sulfide nanoparticles. The reaction took place at ambient atmosphere and temperature inside a fume hood. To obtain around $1 \mathrm{~g}$ of nanoparticles, $10 \mathrm{mmol} \mathrm{Cu}\left(\mathrm{NO}_{3}\right)_{2} \cdot 3 \mathrm{H}_{2} \mathrm{O}$ was dissolved in $35 \mathrm{ml}$ of deionized water in a centrifuge tube using ultrasounds until obtaining a clear light-blue solution. Then, $2 \mathrm{ml}\left(\mathrm{NH}_{4}\right)_{2} \mathrm{~S}$ was injected into the centrifuge tube, which was strongly shaken to force a proper mixing of the reactants. Upon $\left(\mathrm{NH}_{4}\right)_{2} \mathrm{~S}$ injection, the solution turned black owing to the nucleation of copper sulfide through the reaction:

$$
\left(\mathrm{NH}_{4}\right)_{2} \mathrm{~S}+\mathrm{Cu}\left(\mathrm{NO}_{3}\right)_{2} \rightarrow \mathrm{CuS}+2 \mathrm{NH}_{4} \mathrm{NO}_{3}
$$

After 1 min reaction, particles were recovered by centrifugation. Then, they were purified using 5 dispersion/precipitation cycles using deionized water and ethanol. Finally, nanoparticles were dried under vacuum overnight at room temperature and stored in an Ar-filled glovebox.

Nanomaterial consolidation. Dried nanoparticles were annealed at $450{ }^{\circ} \mathrm{C}$ for $180 \mathrm{~min}$ under gas flow inside a tube furnace located inside the glovebox. Two different gas atmospheres were studied: argon and 5\% hydrogen in $\operatorname{argon}\left(\mathrm{Ar} / \mathrm{H}_{2}\right)$. Then, the annealed nanopowders were loaded into a graphite die and hot-pressed at $420{ }^{\circ} \mathrm{C}$ and $60 \mathrm{MPa}$ for 4 min using a custom-made hot press inside the Ar-filled glovebox. ${ }^{28-32}$ The relative densities of the obtained pellets were measured by the Archimedes' method to be $c a .93 \%$ of the theoretical value.

Structural and chemical characterization. X-ray diffraction (XRD, $2 \theta$ angle: $20^{\circ}$ to $80^{\circ}$; scanning rate: $1.5^{\circ} / \mathrm{min}$ ) analyses were carried out on a Bruker AXS D8 ADVANCE X-ray diffractometer with $\mathrm{Cu}-\mathrm{K} \alpha$ radiation $(\lambda=1.5406 \AA)$. Size and morphology of nanoparticles were examined by transmission electron microscopy (TEM) using a ZEISS LIBRA 120, operating at $120 \mathrm{kV}$, and field-emission scanning electron microscopy (SEM) on an Auriga Zeiss operated at $5.0 \mathrm{kV}$. The material composition was analyzed using an Oxford energy dispersive X-ray spectrometer (EDX) attached to a Zeiss Auriga SEM at $20.0 \mathrm{kV}$. Crystallographic structure and chemical composition were analyzed by high resolution TEM 
(HRTEM) and electron energy loss spectroscopy (EELS), respectively, using a Tecnai F20 fieldemission gun microscope at $200 \mathrm{keV}$ with an embedded Gatan QUANTUM image filter. X-ray photoelectron spectroscopy (XPS) was carried out on a Specs system equipped with a Mg anode XR50 source operating at $250 \mathrm{~W}$ and a Phoibos 150 MCD-9 detector (Specs GmbH). The pressure in the analysis chamber was kept below $10^{-7} \mathrm{~Pa}$. Data processing was performed with the CasaXPS program (Casa Software Ltd.).

Thermoelectric Property Measurements. Seebeck coefficients were measured using a static DC method. Electrical resistivity data was obtained by a standard four-probe method. Both the Seebeck coefficient and the electrical resistivity were measured simultaneously in an LSR-3 LINSEIS system in the temperature range between room temperature and $710 \mathrm{~K}$ under helium atmosphere. All samples were measured at least 3 consecutive times during heating up to around $710 \mathrm{~K}$. Taking into account the system accuracy and the measurement precision, an error of $c a$. $4 \%$ in the measurement of the electrical conductivity and Seebeck coefficient was estimated. Thermal conductivities ( $\kappa_{\text {total }}$ ) were obtained by multiplying the thermal diffusivity $(\lambda)$, the constant pressure heat capacity $\left(C_{p}\right)$ and the density of the material $(\rho)$, where $\kappa_{\text {total }}=\lambda C_{p} \rho . A$ Xenon Flash Apparatus XFA600 was used to determine the thermal diffusivities of the samples with an estimated error of $c a .5 \%$. The constant pressure heat capacity $\left(\mathrm{C}_{\mathrm{p}}\right)$ was estimated from empirical formulas by the Dulong-Petit limit (3R law). The density values were measured using the Archimedes' method. To avoid cluttering the plots, error bars were not included in the figures. Hall charge carrier concentrations $\left(n_{H}\right)$ and mobilities $\left(\mu_{H}\right)$ at room temperature were measured with the Van der Pauw method using a magnetic field of $0.6 \mathrm{~T}$ (ezHEMS, NanoMagnetics). 


\section{RESULTS AND DISCUSSIONS}

A rapid, ambient temperature and surfactant-free synthetic protocol was developed to produce copper sulfide nanoparticles using $\left(\mathrm{NH}_{4}\right)_{2} \mathrm{~S}$ and $\mathrm{Cu}\left(\mathrm{NO}_{3}\right)_{2} \cdot 3 \mathrm{H}_{2} \mathrm{O}$ as sulfur and copper precursors, respectively (Figure 1a, see details in the experimental section). Figure 1b,c shows representative SEM and TEM images of the reaction product that consisted in $c a .60 \mathrm{~nm}$ nanoparticles with flat morphology (Figure 1c). XRD analysis showed the crystal structure of the obtained nanoparticles to match the covellite CuS phase (JCPDS No. 01-079-2321).
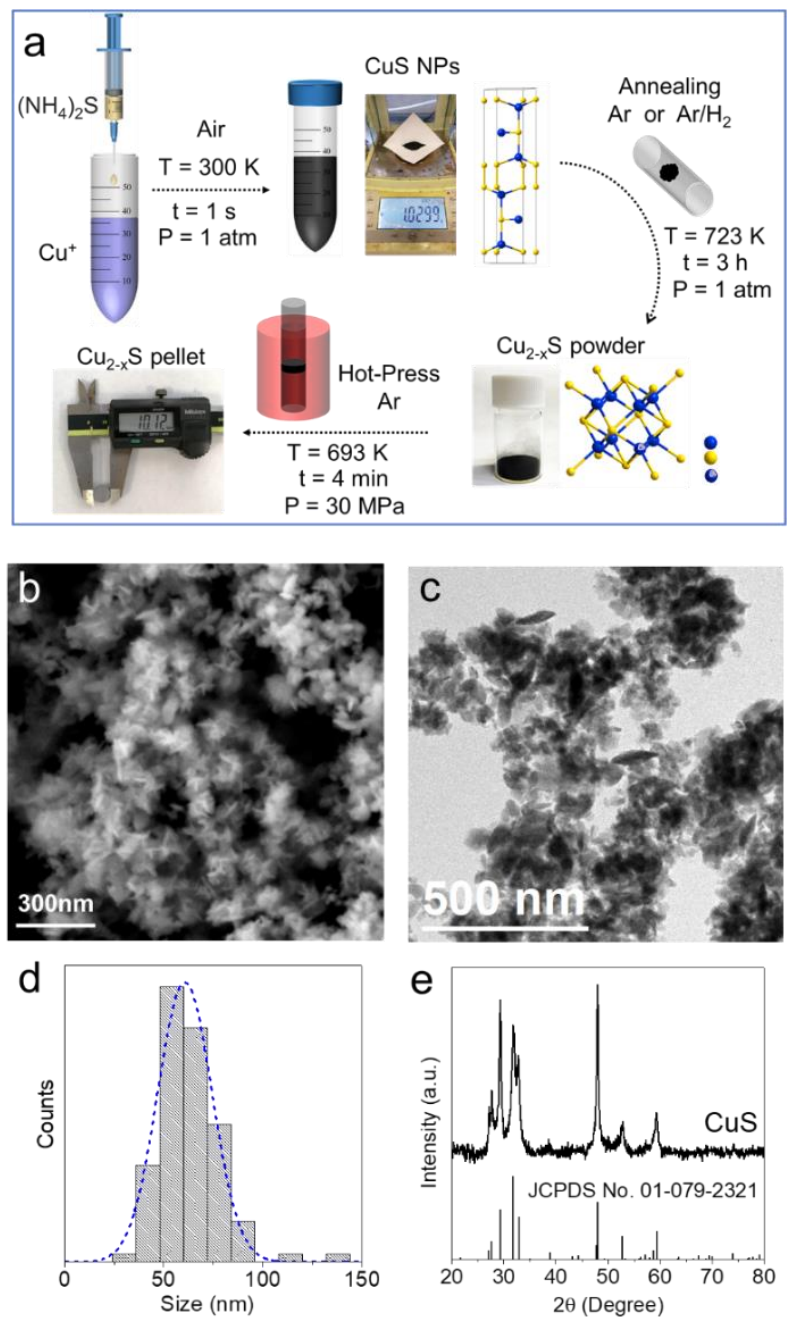

Figure 1. a) Schematic illustration of the three-step process used to produce copper sulfide pellets that involves the synthesis of nanoparticles at ambient pressure and temperature, the annealing of the particles at $723 \mathrm{~K}$ in $\mathrm{Ar}$ or $\mathrm{Ar} / \mathrm{H}_{2}$ atmosphere, and the hot press of the materials at $693 \mathrm{~K}$ and $60 \mathrm{MPa}$. b) SEM micrograph of CuS nanoparticles. c) TEM micrographs of CuS nanoparticles. d) Histogram of the particle size distribution. e) XRD pattern obtained from $\mathrm{CuS}$ nanoparticles. 
HRTEM characterization showed the nanoparticles to have a good crystallinity and confirmed their hexagonal covellite $\mathrm{CuS}$ phase (space group $=\mathrm{P} 63 / \mathrm{mmc}$ ), with $\mathrm{a}=\mathrm{b}=3.7917 \AA$ and $\mathrm{c}=16.3420 \AA$ (Figure 2a). EELS chemical composition maps obtained from the red squared region in the HAADF-STEM micrograph displayed in Figure $2 \mathrm{~b}$ demonstrated a homogeneous distribution of $\mathrm{Cu}$ and $\mathrm{S}$ throughout the particles.

The $\mathrm{Cu} 2 \mathrm{p}_{3 / 2}$ and $\mathrm{S} 2 \mathrm{p}$ high resolution XPS spectra are displayed in Figure $2 \mathrm{c}$. The $\mathrm{Cu} 2 \mathrm{p}$ spectra was fitted with three bands at $933.0 \mathrm{eV}, 935.2 \mathrm{eV}$, and $931.6 \mathrm{eV}$. The $\mathrm{Cu} 2 \mathrm{p}_{3 / 2}$ band at $931.6 \mathrm{eV}$ was associated to $\mathrm{Cu}$ within a $\mathrm{CuS}$ chemical environment. ${ }^{33}$ On the other hand, the two higher energy bands corresponded to two surface oxide components, probably copper oxide and copper sulfate. ${ }^{34}$ The partial surface oxidation of the nanoparticles has its origin on their manipulation and transportation in air, as observed for other materials. ${ }^{33}$ The S $2 p$ XPS spectrum displayed two well-defined doublets at $161.8 \mathrm{eV}$ and $168.2 \mathrm{eV}\left(\mathrm{S} \mathrm{2} \mathrm{p}_{3 / 2}\right)$, which were assigned to lattice $\mathrm{S}$ within $\mathrm{CuS}$ and to sulfate species arising from the surface oxidation of the material, respectively. ${ }^{35}$
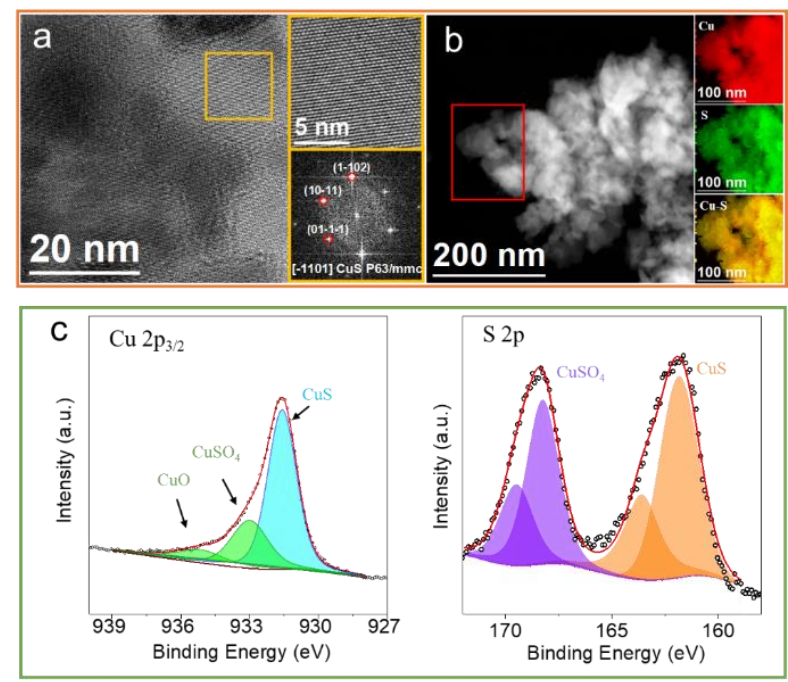

Figure 2. a) HRTEM micrograph, detail of the orange squared region and its corresponding power spectrum. CuS lattice fringe distances were measured to be $0.320 \mathrm{~nm}, 0.323 \mathrm{~nm}$, and $0.304 \mathrm{~nm}$, at $64.46^{\circ}$ and $122.88^{\circ}$ which could be interpreted as the hexagonal CuS phase, visualized along its [-1101] zone axis. b) HAADF-STEM micrograph and EELS chemical composition maps obtained from the red squared area of the STEM micrograph. Individual $\mathrm{Cu} \mathrm{L}_{2,3}$-edges at $931 \mathrm{eV}$ (red) and $\mathrm{S} \mathrm{L}_{2,3}$-edges at 165 $\mathrm{eV}$ (green). c) $\mathrm{Cu} 2 \mathrm{p}_{3 / 2}$ and $\mathrm{S} 2 \mathrm{p}$ high resolution XPS spectra obtained from CuS nanoparticles. 
$\mathrm{CuS}$ nanoparticles were annealed at $723 \mathrm{~K}$ in a tube furnace under gas flow. Two different gases were used for the annealing treatments, $\mathrm{Ar}$ and $5 \% \mathrm{H}_{2}$ in $\mathrm{Ar}\left(\mathrm{Ar} / \mathrm{H}_{2}\right)$. The annealing time was set at $3 \mathrm{~h}$ for $\mathrm{Ar}$, and it was varied between $2 \mathrm{~h}$ and $4 \mathrm{~h}$ for $\mathrm{Ar} / \mathrm{H}_{2}$. Figure 3 displays the room temperature XRD patterns of the annealed powders. Covellite CuS showed to be thermally instable in a sulfur-free atmosphere. Upon heating the particles, $\mathrm{CuS}$ dissociated into $\mathrm{Cu}_{2-\mathrm{x}} \mathrm{S}$ and sulfur that was lost through volatilization. The sample annealed in Ar for $3 \mathrm{~h}$ displayed a metastable rhombohedral $\mathrm{Cu}_{1.8} \mathrm{~S}$ phase at ambient temperature. On the other hand, the $\mathrm{CuS}$ particles annealed in the presence of $\mathrm{H}_{2}$, displayed a larger loss of $\mathrm{S}$. The sample annealed for $2 \mathrm{~h}$ in $\mathrm{Ar} / \mathrm{H}_{2}$ displayed a combination of the metastable rhombohedral $\mathrm{Cu}_{1.8} \mathrm{~S}$ and tetragonal $\mathrm{Cu}_{1.96} \mathrm{~S}$ phases, being the first one the dominant one. After $3 \mathrm{~h}$ at $450{ }^{\circ} \mathrm{C}$ in an $\mathrm{Ar} / \mathrm{H}_{2}$ atmosphere, the rhombohedral phase was still visible, but the tetragonal phase became majoritarian and the monoclinic $\mathrm{Cu}_{2} \mathrm{~S}$ phase appeared. When increasing the annealing time to $4 \mathrm{~h}$ in $\mathrm{Ar} / \mathrm{H}_{2}$, a combination of monoclinic $\mathrm{Cu}_{2} \mathrm{~S}$ and tetragonal $\mathrm{Cu}_{1.96} \mathrm{~S}$ was obtained, being the monoclinic the main phase.
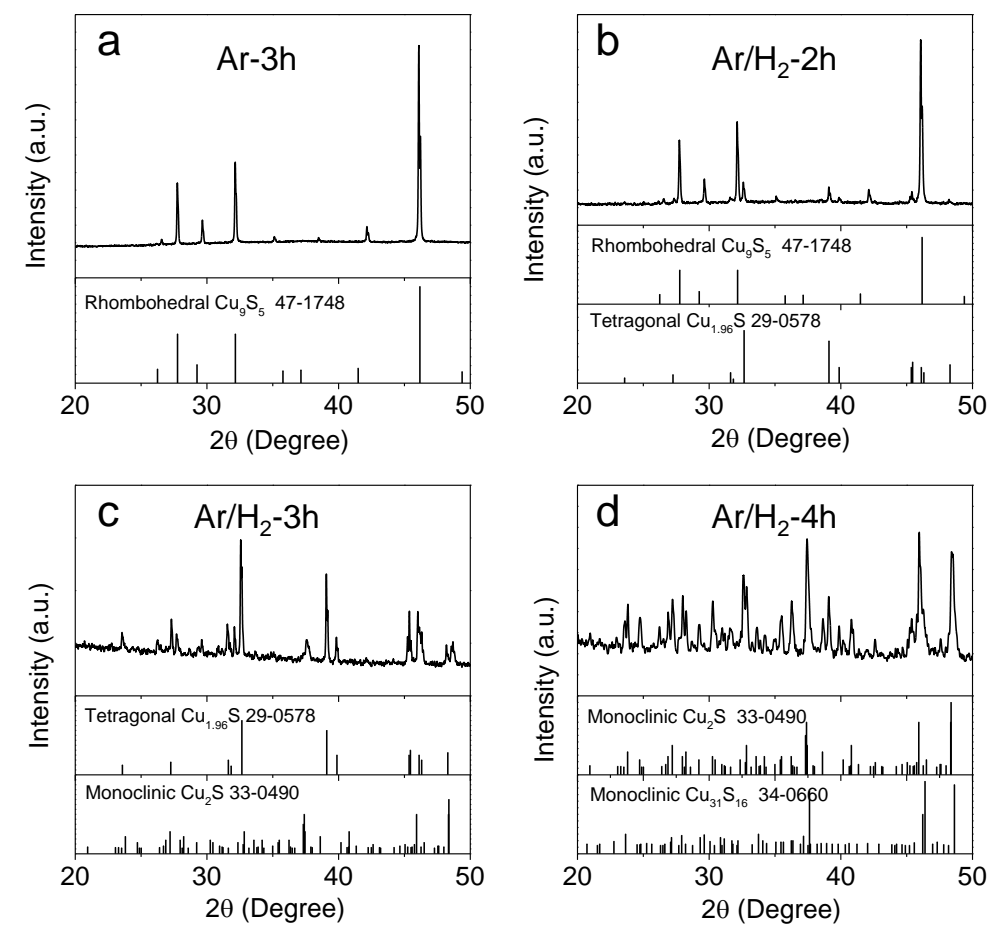

Figure 3. $\mathrm{XRD}$ patterns of $\mathrm{Cu}_{2-\mathrm{x}} \mathrm{S}$ powders obtained from annealing covellite $\mathrm{CuS}$ nanoparticles under different gas flow, $\mathrm{Ar}$ or $\mathrm{Ar} / \mathrm{H}_{2}$, and different times, from $2 \mathrm{~h}$ to $4 \mathrm{~h}$, as indicated in each pattern. 
SEM characterization of the annealed powders showed the $\mathrm{Cu}_{2-\mathrm{x}} \mathrm{S}$ particles to grow during the thermal treatment, independently of the used gas flow (Figure S1). EDX analysis further confirmed the sulfur composition to strongly decrease with the annealing process and the final $\mathrm{Cu} / \mathrm{S}$ ratio to be higher for the sample annealed in the presence of $\mathrm{H}_{2}$ (Table S1). Figures $\mathrm{S} 2$ and S3 display representative HRTEM images and EELS compositional maps of the samples annealed for $3 \mathrm{~h}$ under $\mathrm{Ar}$ or $\mathrm{Ar} / \mathrm{H}_{2}$ flow. The power spectrum analysis of the HRTEM micrographs showed the sample annealed in Ar to display the stable $\mathrm{Cu} 1.8 \mathrm{~S}$ cubic phase (space group $=\mathrm{F} 4-3 \mathrm{M}$ ) with $\mathrm{a}=\mathrm{b}=\mathrm{c}=5.3870 \AA$, instead of the metastable rhombohedral $\mathrm{Cu}_{1.8} \mathrm{~S}$ phase observed by XRD. On the other hand, the sample annealed under $\mathrm{Ar} / \mathrm{H}_{2}$ flow displayed the stable monoclinic $\mathrm{P} 121 \mathrm{Cu}_{1.96} \mathrm{~S}$ djulerite structure instead of the metastable tetragonal $\mathrm{Cu}_{1.96} \mathrm{~S}$ displayed by the XRD pattern. These inconsistencies between XRD and HRTEM data could be related to the transformation of the metastable phases under the electron beam during HRTEM analysis. EELS chemical composition maps of both samples displayed a uniform distribution of $\mathrm{Cu}$ and $\mathrm{S}$ (Figures S3b and S4b).

Annealed powders were subsequently loaded into a $10 \mathrm{~mm}$ graphite die and hot-pressed at 693 $\mathrm{K}$ and $60 \mathrm{MPa}$ for $4 \mathrm{~min}$ inside an Ar-filled glove box. The relative densities of the obtained pellets were $c a .93 \%$ of the theoretical value, as measured by the Archimedes' method. XRD analysis of the pellets showed a minor influence of the hot-press treatment on the crystallographic phase of $\mathrm{Cu}_{2-\mathrm{x}} \mathrm{S}$ (Figure 4). The XRD patterns of the pellets obtained from nanoparticles annealed in $\mathrm{Ar}$ and $\mathrm{Ar} / \mathrm{H}_{2}$ displayed the metastable rhombohedral $\mathrm{Cu}_{1.8} \mathrm{~S}$ and tetragonal $\mathrm{Cu}_{1.96} \mathrm{~S}$ phases, respectively, consistently with the results obtained from the nanopowders. These pellets were used to characterize thermoelectric properties. 

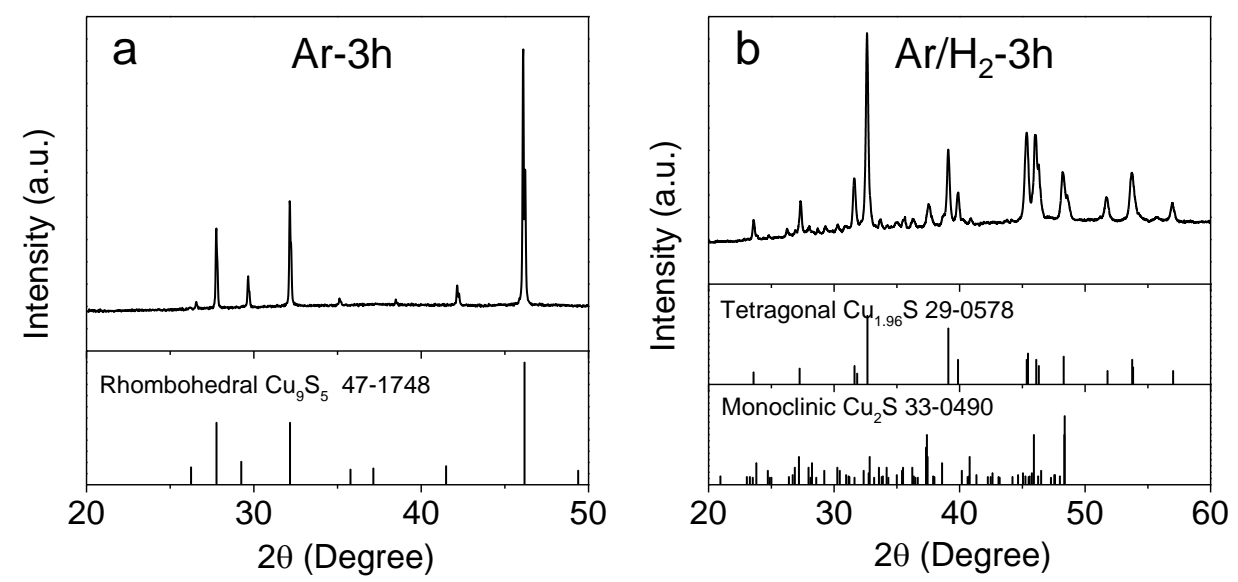

Figure 4. XRD patterns of $\mathrm{Cu}_{2-\mathrm{x}} \mathrm{S}$ pellets obtained by annealing the covellite $\mathrm{CuS}$ NPs for $3 \mathrm{~h}$ under different gas flow, $\mathrm{Ar}$ (a)or $\mathrm{Ar} / \mathrm{H}_{2}$ (b), as indicated in each pattern, and afterward hot pressing the obtained powder at $693 \mathrm{~K}$ and $60 \mathrm{MPa}$.

Figure 5 displays the electrical conductivity $(\sigma)$, Seebeck coefficient $(\mathrm{S})$, and power factor $\left(\mathrm{PF}=\mathrm{S}^{2} \sigma\right)$ of the $\mathrm{Cu}_{2-\mathrm{x}} \mathrm{S}$ pellets in the temperature range $310-710 \mathrm{~K}$. The first measuring cycle showed slightly different results for all samples compared with the subsequent ones (Figure S4). Thus the results obtained in the second cycle, which coincide with results obtained in following cycles, are the ones presented here. Compared with samples annealed in Ar, an order of magnitude lower electrical conductivities were obtained for the samples annealed in the presence of $\mathrm{H}_{2}$ for $3-4 \mathrm{~h}$. This decrease of $\sigma$ was correlated with a substantial increase of the Seebeck coefficient. Both, the $\sigma$ decrease and the $\mathrm{S}$ increase with the annealing in the presence of $\mathrm{H}_{2}$ were related to a strong reduction of the charge carrier concentration, from $8 \times 10^{20} \mathrm{~cm}^{-3}$ for the sample annealed in Ar to $6 \times 10^{19} \mathrm{~cm}^{-3}$ for the sample annealed in $\mathrm{Ar} / \mathrm{H}_{2}$ for $3 \mathrm{~h}$, as measured by Hall (Table S2). This decrease of the charge carrier concentration was consistent with the higher $\mathrm{Cu} / \mathrm{S}$ ratio and thus the lower density of $\mathrm{Cu}$ vacancies obtained in samples annealed in $\mathrm{Ar} / \mathrm{H}_{2}$. Overall, power factors were significantly larger for samples annealed in $\mathrm{Ar} / \mathrm{H}_{2}$ for 2-3 $\mathrm{h}$ than for samples annealed in $\mathrm{Ar}$. These results demonstrate that $\mathrm{Cu}_{2-\mathrm{x}} \mathrm{S}$ transport properties can be easily tuned by just modifying the parameters of annealing of $\mathrm{CuS}$ nanoparticles, and particularly the annealing atmosphere.

The transport properties of the samples annealed under $\mathrm{Ar} / \mathrm{H}_{2}$ showed a non-monotonous 
dependence on temperature. Taking the electrical conductivity as a reference (Figure 5a), when increasing temperature, $\sigma$ of samples annealed in the presence of $\mathrm{H}_{2}$ increased up to $350-450 \mathrm{~K}$, then decreased until 600-650 K, and then increased again in samples annealed for $3 \mathrm{~h}$ and above. This complex variation of the thermoelectric parameters with temperature was consistently observed for different samples and measuring cycles, except for the first one (Figure S4).
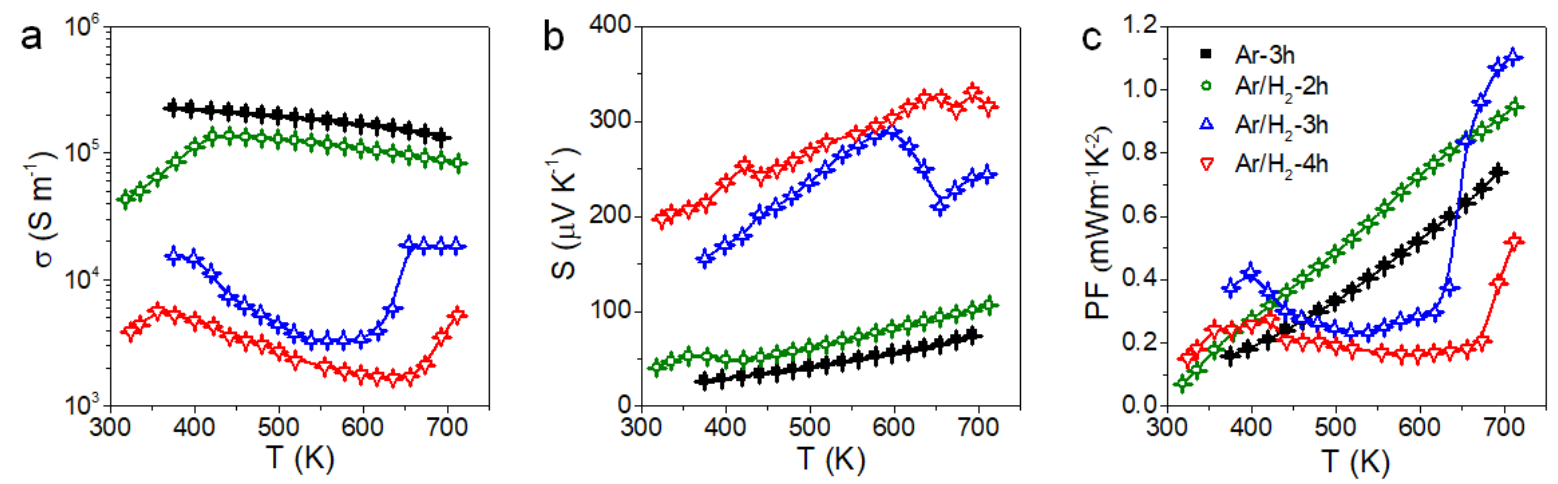

Figure 5. Thermoelectric properties of $\mathrm{Cu}_{2-\mathrm{x}} \mathrm{S}$ samples annealed under different gas flow and for different times: a) electrical conductivity, $\sigma$; b) Seebeck coefficient, $S$; c) power factor, PF.

To determine the origin of this complex behavior, we analyzed the crystal structure of the material after the first measurement cycle and the evolution of the crystal structure with temperature (Figure S5). After the first measurement cycle up to $710 \mathrm{~K}$, the pellet obtained from the covellite nanoparticles annealed in Ar displayed mainly the monoclinic djurleite $\mathrm{Cu} 1.97 \mathrm{~S}$ phase. On the other hand, the pellet obtained from covellite particles annealed in $\mathrm{Ar} / \mathrm{H}_{2}$ displayed a combination of monoclinic $\mathrm{Cu}_{1.96} \mathrm{~S}$ and $\mathrm{Cu}_{2} \mathrm{~S}$ phases. Figures 6 and S6 display the $\mathrm{XRD}$ patterns measured at different temperatures from $\mathrm{Cu}_{2-\mathrm{x}} \mathrm{S}$ pellets produced from NPs annealed in $\mathrm{Ar}$ (Figures 6a, S6a) and $\mathrm{Ar} / \mathrm{H}_{2}$ (Figures 6b, S6b).

The monoclinic djurlite phase measured at ambient temperature from the $\mathrm{Cu}_{2-\mathrm{x}} \mathrm{S}$ pellet obtained from nanoparticles annealed in Ar evolved with temperature to a cubic $\mathrm{Cu}_{2} \mathrm{~S}$ phase. This phase transition occurred in the temperature range $350-450 \mathrm{~K}$ and the cubic phase was maintained up to $710 \mathrm{~K}$. On the other hand, when increasing temperature, the $\mathrm{Cu}_{2-\mathrm{x}} \mathrm{S}$ pellet produced from nanoparticles annealed in $\mathrm{Ar} / \mathrm{H}_{2}$ underwent phase transition from the combination of monoclinic djurleite and chalcocite measured at ambient temperature to increasingly more symmetric structures. In the temperature range 350 - $400 \mathrm{~K}$ the monoclinic phases evolved into 
the hexagonal high chalcocite $\mathrm{Cu}_{2} \mathrm{~S}$ phase. This transition coincided with the first anomaly in the evolution of the transport properties of this material. A second phase transition, from hexagonal to cubic $\mathrm{Cu}_{2} \mathrm{~S}$, was observed at 500-600 K, coinciding with the second anomaly on the temperature evolution of the transport properties.
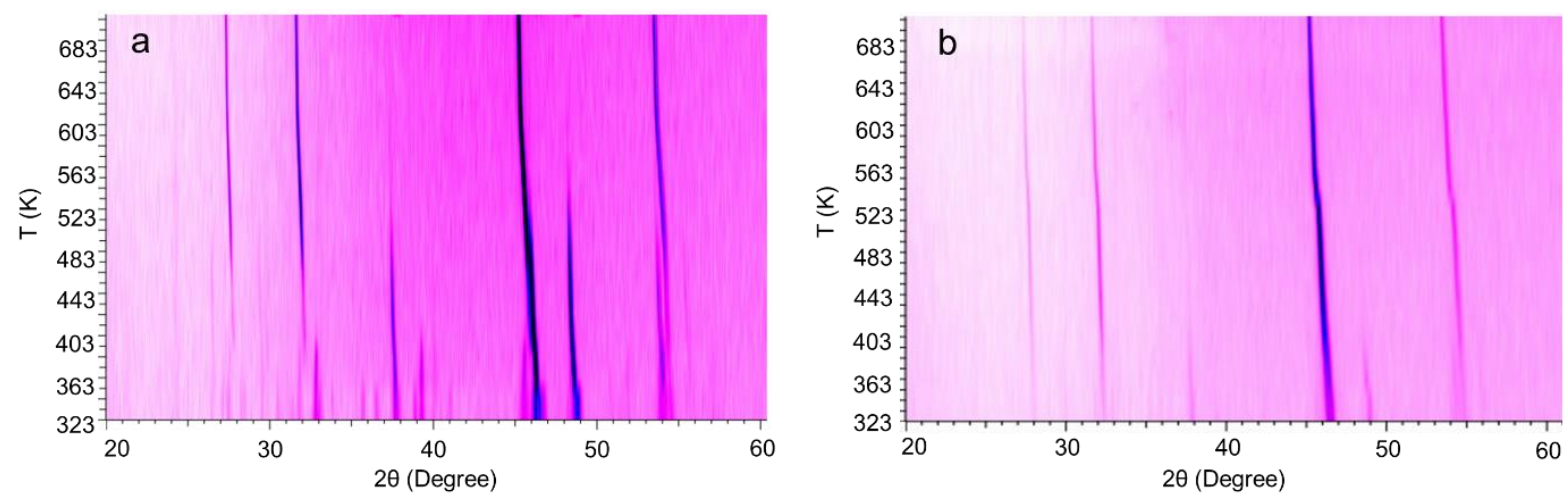

Figure 6. Evolution of the XRD patterns of $\mathrm{Cu}_{2-\mathrm{x}} \mathrm{S}$ pellets obtained from nanoparticles annealed in $\mathrm{Ar}$ (a) or $\mathrm{Ar} / \mathrm{H}_{2}$ (b). XRD patterns were measured from the pellets after thermoelectric property measurement and were obtained when increasing temperature (from bottom to top) in the temperature range from $323 \mathrm{~K}$ to $703 \mathrm{~K}$.

Figure 7a shows the thermal conductivity ( $\kappa_{\text {total }}$ ) of the $\mathrm{Cu}_{2-\mathrm{x}} \mathrm{S}$ pellets annealed in $\mathrm{Ar}$ or $\mathrm{Ar} / \mathrm{H}_{2}$ for $3 \mathrm{~h}$. The thermal conductivity of the sample annealed in Ar was significantly higher than that of the sample annealed in $\mathrm{Ar} / \mathrm{H}_{2}$ owing to the much larger contribution from the electronic thermal conductivity in the former. When subtracting the electronic contribution, $\kappa_{\mathrm{e}}=\mathrm{L}_{0} \sigma \mathrm{T}$ where $\mathrm{L}_{0}$ is the Lorenz number, we observe the lattice thermal conductivity of the two materials annealed in different conditions to be similar (Figure 7b).

The dimensionless thermoelectric figure of merit $\left(\mathrm{ZT}=\mathrm{S}^{2} \sigma \mathrm{T} / \mathrm{k}\right)$ of the $\mathrm{Cu}_{2-\mathrm{x}} \mathrm{S}$ pellets annealed in $\mathrm{Ar}$ and $\mathrm{Ar} / \mathrm{H}_{2}$ for $3 \mathrm{~h}$ are displayed in figure 7c. Compared with the material annealed in $\mathrm{Ar}$, the material annealed in $\mathrm{Ar} / \mathrm{H}_{2}$ for $3 \mathrm{~h}$ was characterized by a much higher figure of merit, reaching up to $\mathrm{ZT}=1.37$ at $710 \mathrm{~K}$. To the best of our knowledge, this is the highest $\mathrm{ZT}$ value reported for $\mathrm{Cu}_{2-\mathrm{x}} \mathrm{S}$ in this middle temperature range, where $\mathrm{Cu}_{2-\mathrm{x}} \mathrm{S}$ displays a stable behavior (Figures 7d, S7). 

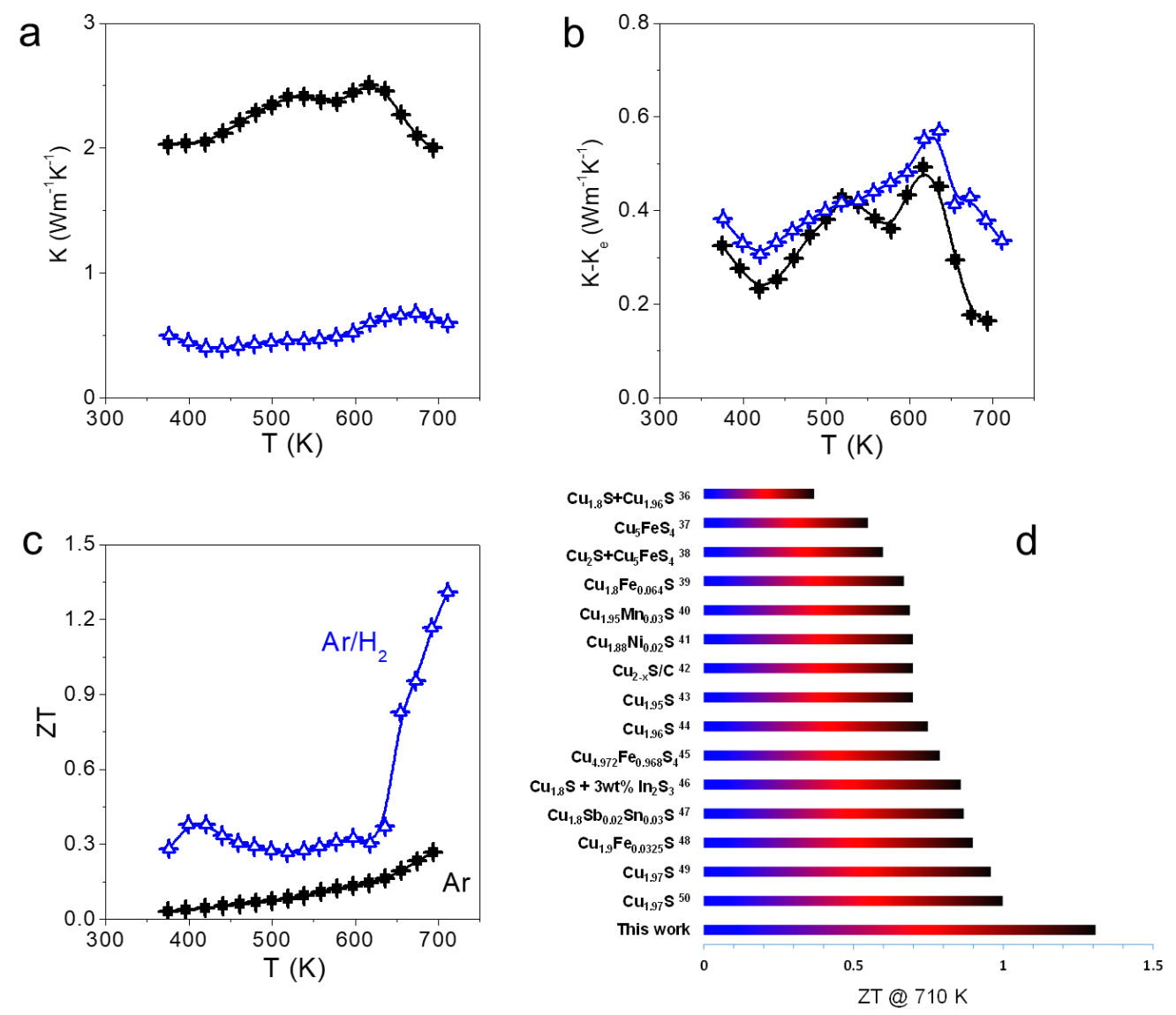

Figure 7. Thermoelectric properties of $\mathrm{Cu}_{2-\mathrm{x}} \mathrm{S}$ pellets obtained from nanoparticles annealed under $\mathrm{Ar}$ (black solid symbols) and $\mathrm{Ar} / \mathrm{H}_{2}$ (blue open symbols): a) thermal conductivity, $\kappa_{\text {total }}$; b) lattice thermal conductivity, $\kappa_{\mathrm{L}} ; \mathrm{c}$ ) thermoelectric figure of merit, ZT; Comparison of ZT values at $710 \mathrm{~K}$ for $\mathrm{Cu}_{2-\mathrm{x}} \mathrm{S}$-based materials. ${ }^{36-50}$

The excellent performances measured from materials initially produced in nanoparticle form demonstrates the high suitability of the presented material processing strategy. We believe that the synthesis of copper sulfide in the form of nanoparticles is key both to reduce production cost, as no large amounts of energy and time are invested in organizing atoms in large crystal domains, and to control composition by means of a mild thermal annealing in a controlled atmosphere. Besides, the availability of the material in the form of nanoparticles suspended in a low-cost and safe solvent such as water allows producing devices using printing technologies. To advance in this direction, we prepared inks using the annealed nanoparticles and printed them on a mica substrate (Figure 8). Then we hot-pressed the films in the same conditions as the pellets. Figure $8 \mathrm{~b}-\mathrm{d}$ displays the thermoelectric properties of the films obtained from $\mathrm{Cu}_{2}-$ 
${ }_{x} \mathrm{~S}$ nanoparticles annealed under $\mathrm{Ar}$ or $\mathrm{Ar} / \mathrm{H}_{2}$ flow for $3 \mathrm{~h}$. The results obtained from the films were very similar to those obtained from pellets, which demonstrates the potential of these nanoparticle-based material to produce thermoelectric devices using cost-effective and highthroughput printing technologies.
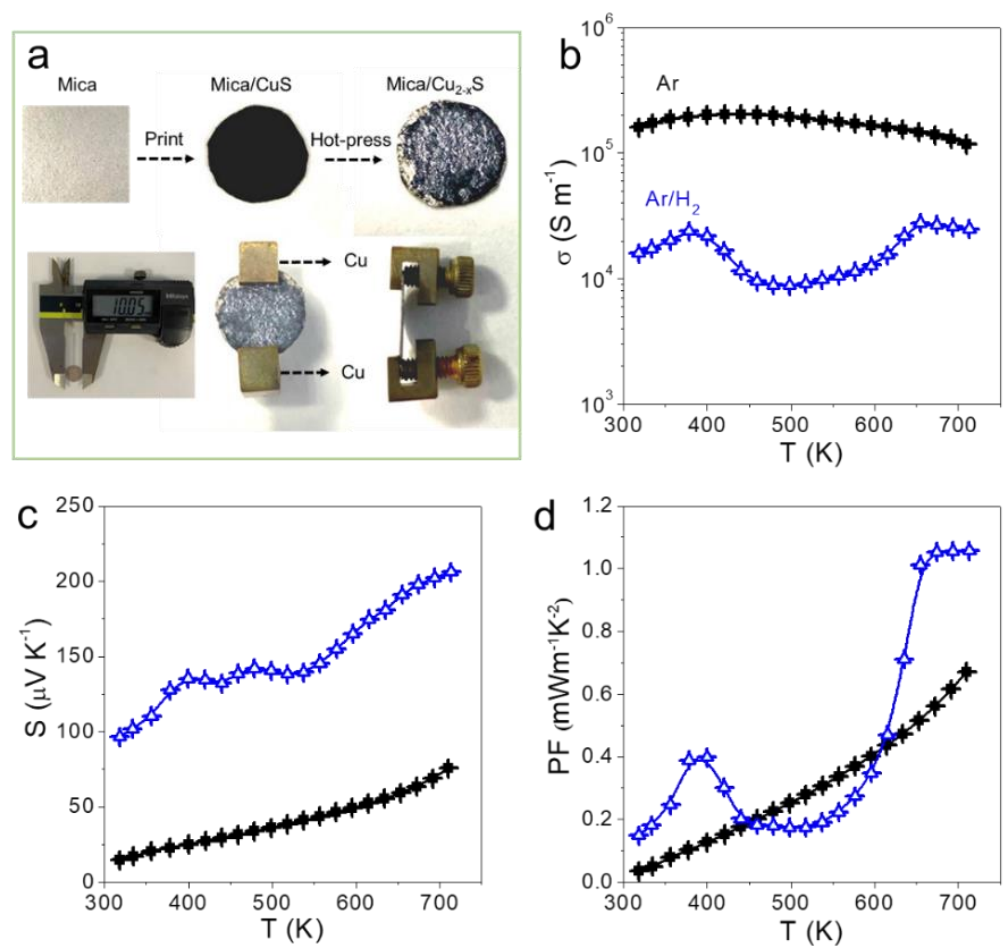

Figure 8. Schematic illustration of devices of copper sulfide produced by printing. Thermoelectric properties of the $\mathrm{Cu}_{2-\mathrm{x}} \mathrm{S}$ films: a) electrical conductivity, $\sigma$; b) Seebeck coefficient, $\mathrm{S}$; c) power factor, PF. 


\section{CONCLUSIONS}

We reported a facile, scalable and low-cost method for the synthesis of covellite $\mathrm{CuS}$ nanoparticles in aqueous media and at room temperature. The produced covellite nanoparticles lose sulfur when heated under inert or reducing atmosphere, and change their crystal phase to metastable rhombohedral $\mathrm{Cu}_{1.8} \mathrm{~S}$ or tetragonal $\mathrm{Cu}_{1.96} \mathrm{~S}$. The annealing atmosphere and time allowed tuning the amount of sulfur lost and thus the stoichiometry and crystal structure of the final material. The sample stoichiometry determines the density of copper vacancies formed, thus the hole concentration and consequently the transport properties of the material. Comparing the material annealed in Ar with the annealed in $\mathrm{Ar} / \mathrm{H}_{2}$, we observe the former to be characterized by much higher charge carrier concentrations and electrical conductivities, but much lower Seebeck coefficients. Overall, the material annealed in $\mathrm{Ar} / \mathrm{H} 2$ for $3 \mathrm{~h}$ was characterized with the highest power factors and thermoelectric figures of merit, up to 1.31 at $710 \mathrm{~K}$, which is the highest $\mathrm{ZT}$ reported for $\mathrm{Cu}_{2-\mathrm{x}} \mathrm{S}$ at this temperature. The availability of the material in the form of nanoparticles also allowed the direct printing of the material in the form of films. The printed films were characterized by similar thermoelectric performances as those obtained from the pellets.

\section{ACKNOWLEDGEMENT}

This work was supported by the European Regional Development Funds. MYL, YZ and KX thank the China Scholarship Council for scholarship support. 


\section{REFERENCES}

(1) Coughlan, C.; Ibáñez, M.; Dobrozhan, O.; Singh, A.; Cabot, A.; Ryan, K. M.

Compound Copper Chalcogenide Nanocrystals. Chem. Rev. 2017, 117 (9), 5865-6109. https://doi.org/10.1021/acs.chemrev.6b00376.

(2) Goble, R. J. Relationship Between Crystal Structure, Bonding and Cell Dimensions in the Copper Sulfides. Can. Mineral. 1985, 23 (pt 1), 61-76.

(3) Lukashev, P.; Lambrecht, W. R. L.; Kotani, T.; Van Schilfgaarde, M. Electronic and Crystal Structure of Cu2-x S: Full-Potential Electronic Structure Calculations. Phys. Rev. B - Condens. Matter Mater. Phys. 2007, 76 (19), 1-14. https://doi.org/10.1103/PhysRevB.76.195202.

(4) Evans, H. T. The Crystal Structures of Low Chalcocite and Djurleite. Zeitschrift fur Krist. - New Cryst. Struct. 1979, 150 (1-4), 299-320. https://doi.org/10.1524/zkri.1979.150.1-4.299.

(5) Luther, J. M.; Jain, P. K.; Ewers, T.; Alivisatos, A. P. Localized Surface Plasmon Resonances Arising from Free Carriers in Doped Quantum Dots. Nat. Mater. 2011, 10 (5), 361-366. https://doi.org/10.1038/nmat3004.

(6) Zimmer, D.; Ruiz-Fuertes, J.; Bayarjargal, L.; Haussühl, E.; Winkler, B.; Zhang, J.; Jin, C. Q.; Milman, V.; Alig, E.; Fink, L. Phase Transition of Tetragonal Copper Sulfide $\mathrm{Cu} 2 \mathrm{~S}$ at Low Temperatures. Phys. Rev. B 2017, 96 (5), 1-11. https://doi.org/10.1103/PhysRevB.96.054108.

(7) Mumme, G.; Gable, W. THE CRYSTAL STRUCTURE OF ROXBYITE, Cu 58 S 32. Can. Mineral. 2012, 50, 423-430.

(8) Li, W.; Shavel, A.; Guzman, R.; Rubio-Garcia, J.; Flox, C.; Fan, J.; Cadavid, D.; Ibáñez, M.; Arbiol, J.; Morante, J. R.; Cabot, A. Morphology Evolution of Cu2-XS Nanoparticles: From Spheres to Dodecahedrons. Chem. Commun. 2011, 47 (37), 10332-10334. https://doi.org/10.1039/c1cc13803k.

(9) Will, G.; Hinze, E.; Abdelrahman, A. R. M. Crystal Structure Analysis and Refinement 
of Digenite, Cu1.8S, in the Temperature Range 20 to $500 \mathrm{C}$ under Controlled Sulfur Partial Pressure. Eur. J. Mineral. 2002, 14 (3), 591-598. https://doi.org/10.1127/0935$1221 / 2002 / 0014-0591$

(10) Koto, K.; Morimoto, N. The Crystal Structure of Anilite. Acta Crystallogr. Sect. B Struct. Crystallogr. Cryst. Chem. 1970, 26 (7), 915-924. https://doi.org/10.1107/s0567740870003370.

(11) Momuoro, N. PHASE RELATIONS OF THE CU-S SYSTEM AT LOW TEMPERATURES : STABILITY OF . ANILITE. Amercan Mineral. 1970, 55 (119).

(12) Gotsis, H. J.; Barnes, A. C.; Strange, P. Experimental and Theoretical Investigation of the Crystal Structure of CuS. J. Phys. Condens. Matter 1992, 4 (50), 10461-10468. https://doi.org/10.1088/0953-8984/4/50/034.

(13) Luther, G. W.; Theberge, S. M.; Rozan, T. F.; Rickard, D.; Rowlands, C. C.; Oldroyd, A. Aqueous Copper Sulfide Clusters as Intermediates during Copper Sulfide Formation. Environ. Sci. Technol. 2002, 36 (3), 394-402. https://doi.org/10.1021/es010906k.

(14) Pattrick, R. A. D.; Mosselmans, J. F. W.; Charnock, J. M.; England, K. E. R.; Helz, G. R.; Garner, C. D.; Vaughan, D. J. The Structure of Amorphous Copper Sulfide Precipitates: An X-Ray Absorption Study. Geochim. Cosmochim. Acta 1997, 61 (10), 2023-2036. https://doi.org/10.1016/S0016-7037(97)00061-6.

(15) Skinner, B. Tecnología de La Enseñanza. Tecnol. la Enseñanza 1970, 157.

(16) Roseboom, H. An Investigation of the System Cu-S and Some Natural Copper Sulfides Between $25^{\circ}$ and $700^{\circ}$ C. Econ. Geol. 1966, 61, 641-672.

(17) Djurle, S.; Sørensen, P.; Stenhagen, E.; Hartiala, K.; Veige, S.; Diczfalusy, E. An XRay Study on the System Ag-Cu-S. Acta Chemica Scandinavica. 1958, pp 1427-1436. https://doi.org/10.3891/acta.chem.scand.12-1427.

(18) Morimoto, N., Kullerud, G. 1 Present Addtess: Mineralogical Institute, 110 University of Tokyo, Tokyo, Japan. Am. Mineral. 1963, 48 (November), 110-123. 
(19) Liu, L.; Zhong, H.; Bai, Z.; Zhang, T.; Fu, W.; Shi, L.; Xie, H.; Deng, L.; Zou, B. Controllable Transformation from Rhombohedral Cu1.8S Nanocrystals to Hexagonal CuS Clusters: Phase- and Composition-Dependent Plasmonic Properties. Chem. Mater. 2013, 25 (23), 4828-4834. https://doi.org/10.1021/cm403420u.

(20) Kawai, S. Electrical Conduction and Phase Transition of Copper Sulfides. Jpn. J. Appl. Phys. 1973, 12 (8), 1130-1138. https://doi.org/10.1143/JJAP.12.1130.

(21) Mihaly Posfai, P. R. B. Djurleite,Digenite, and Chalcocite:Intergrowths and Transformations. Amecican Mineral. 1994, 79, 308-315. https://doi.org/10.36074/13.03.2020.v2.24.

(22) Potter, R. W. An Electrochemical Investigation of the System Copper-Sulfur. Econ. Geol. 1977, 72 (8), 1524-1542. https://doi.org/10.2113/gsecongeo.72.8.1524.

(23) American, T. H. E. The American Mineralogist, Vol. 54, September-October' 1969. Am. Mineral. 1969, 54, 1256-1268.

(24) Rivest, J. B.; Fong, L.-K.; Jain, P. K.; Toney, M. F.; Alivisatos, A. P. Size Dependence of a Temperature-Induced Solid-Solid Phase Transition in Copper(I) Sulfide. J. Phys. Chem. Lett. 2011, 2 (19), 2402-2406. https://doi.org/10.1021/jz2010144.

(25) Wu, Y.; Wadia, C.; Ma, W.; Sadtler, B.; Alivisatos, A. P. Synthesis and Photovoltaic Application of Copper(1) Sulfide Nanocrystals. Nano Lett. 2008, 8 (8), 2345-2350. https://doi.org/10.1021/nl801817d.

(26) Comin, A.; Manna, L. New Materials for Tunable Plasmonic Colloidal Nanocrystals. Chem. Soc. Rev. 2014, 43 (11), 3957-3975. https://doi.org/10.1039/c3cs60265f.

(27) Qiu, P.; Zhu, Y.; Qin, Y.; Shi, X.; Chen, L. Electrical and Thermal Transports of Binary Copper Sulfides CuxS with x from 1.8 to 1.96. APL Mater. 2016, 4 (10). https://doi.org/10.1063/1.4953439.

(28) Liu, Y.; Zhang, Y.; Lim, K. H.; Ibáñez, M.; Ortega, S.; Li, M.; David, J.; MartíSánchez, S.; Ng, K. M.; Arbiol, J.; Kovalenko, M. V.; Cadavid, D.; Cabot, A. High Thermoelectric Performance in Crystallographically Textured N-Type Bi2Te3- XSex 
Produced from Asymmetric Colloidal Nanocrystals. ACS Nano 2018, 12 (7), 71747184. https://doi.org/10.1021/acsnano.8b03099.

(29) Liu, Y.; Zhang, Y.; Ortega, S.; Ibáñez, M.; Lim, K. H.; Grau-Carbonell, A.; MartíSánchez, S.; Ng, K. M.; Arbiol, J.; Kovalenko, M. V.; Cadavid, D.; Cabot, A. Crystallographically Textured Nanomaterials Produced from the Liquid Phase Sintering of BixSb2-XTe3 Nanocrystal Building Blocks. Nano Lett. 2018, 18 (4), 2557-2563. https://doi.org/10.1021/acs.nanolett.8b00263.

(30) Ortega, S.; Ibáñez, M.; Liu, Y.; Zhang, Y.; Kovalenko, M. V.; Cadavid, D.; Cabot, A. Bottom-up Engineering of Thermoelectric Nanomaterials and Devices from SolutionProcessed Nanoparticle Building Blocks. Chem. Soc. Rev. 2017, 46 (12), 3510-3528. https://doi.org/10.1039/c6cs00567e.

(31) Li, M.; Liu, Y.; Zhang, Y.; Zuo, Y.; Li, J.; Lim, K. H.; Cadavid, D.; Ng, K. M.; Cabot, A. Crystallographically Textured SnSe Nanomaterials Produced from the Liquid Phase Sintering of Nanocrystals. Dalt. Trans. 2019, 48 (11), 3641-3647. https://doi.org/10.1039/c8dt04414g.

(32) Zhang, Y.; Liu, Y.; Lim, K. H.; Xing, C.; Li, M.; Zhang, T.; Tang, P.; Arbiol, J.; Llorca, J.; Ng, K. M.; Ibáñez, M.; Guardia, P.; Prato, M.; Cadavid, D.; Cabot, A. Tin Diselenide Molecular Precursor for Solution-Processable Thermoelectric Materials. Angew. Chemie 2018, 130 (52), 17309-17314. https://doi.org/10.1002/ange.201809847.

(33) Biesinger, M. C. Advanced Analysis of Copper X-Ray Photoelectron Spectra. Surf. Interface Anal. 2017, 49 (13), 1325-1334. https://doi.org/10.1002/sia.6239.

(34) Larson, P. E. X-Ray Induced Photoelectron and Auger Spectra of $\mathrm{Cu}, \mathrm{CuO}, \mathrm{Cu} 2 \mathrm{O}$, and Cu2S Thin Films. J. Electron Spectros. Relat. Phenomena 1974, 4 (3), 213-218. https://doi.org/10.1016/0368-2048(74)80052-6.

(35) Zuo, Y.; Liu, Y.; Li, J.; Du, R.; Han, X.; Zhang, T.; Arbiol, J.; Divins, N. J.; Llorca, J.; Guijarro, N.; Sivula, K.; Cabot, A. In Situ Electrochemical Oxidation of Cu2S into 
$\mathrm{CuO}$ Nanowires as a Durable and Efficient Electrocatalyst for Oxygen Evolution Reaction. Chem. Mater. 2019, 31 (18), 7732-7743.

https://doi.org/10.1021/acs.chemmater.9b02790.

(36) Gu, S. W.; Zhang, Y. X.; Guo, J.; Feng, J.; Ge, Z. H. Effects of Sintering Temperature on Thermoelectric Properties of Cu1.8S Bulk Materials. Mater. Res. Express 2020, 7 (1). https://doi.org/10.1088/2053-1591/ab6c14.

(37) Singh, M.; Dwivedi, P.; Mott, D.; Higashimine, K.; Ohta, M.; Miwa, H.; Akatsuka, T.; Maenosono, S. Colloid Chemical Approach for Fabricating $\mathrm{Cu}-\mathrm{Fe}-\mathrm{S}$ Nanobulk Thermoelectric Materials by Blending $\mathrm{Cu} 2 \mathrm{~S}$ and FeS Nanoparticles as Building Blocks. Ind. Eng. Chem. Res. 2019, 58, 3688-3697. https://doi.org/10.1021/acs.iecr.8b05569.

(38) Mikuła, A.; Nieroda, P.; Mars, K.; Dąbrowa, J.; Koleżyński, A. Structural, Thermoelectric and Stability Studies of Fe-Doped Copper Sulfide. Solid State Ionics 2020, 350 (November 2019), 115322. https://doi.org/10.1016/j.ssi.2020.115322.

(39) Mao, T.; Qiu, P.; Liu, J.; Du, X.; Hu, P.; Zhao, K.; Ren, D.; Shi, X.; Chen, L. Good Stability and High Thermoelectric Performance of Fe Doped Cu1.80S. Phys. Chem. Chem. Phys. 2020, 22 (14), 7374-7380. https://doi.org/10.1039/d0cp00733a.

(40) Liang, X.; Jin, D.; Dai, F. Phase Transition Engineering of $\mathrm{Cu} 2 \mathrm{~S}$ to Widen the Temperature Window of Improved Thermoelectric Performance. AEM 2019, 1900486, 1-9. https://doi.org/10.1002/aelm.201900486.

(41) Shen, F.; Zheng, Y.; Miao, L.; Liu, C.; Gao, J.; Wang, X.; Liu, P.; Yoshida, K.; Cai, H. Boosting High Thermoelectric Performance of Ni-Doped Cu 1.9 S by Signi Fi Cantly Reducing Thermal Conductivity. AMI 2020. https://doi.org/10.1021/acsami.9b18078.

(42) Chen, X.; Zhang, H.; Zhao, Y.; Liu, W.; Dai, W.; Wu, T.; Lu, X.; Wu, C.; Luo, W.; Fan, Y.; Wang, L.; Jiang, W.; Chen, Z.; Yang, J. Carbon-Encapsulated Copper Sul Fi de Leading to Enhanced Thermoelectric Properties. ACS Appl. Mater. Interfaces 2019, 11, 22457-22463. https://doi.org/10.1021/acsami.9b06212. 
(43) Cu, À. S. Kinetic Condition Driven Phase and Vacancy Enhancing Thermoelectric Performance Of. JMCC 2019, 5366-5373. https://doi.org/10.1039/c9tc00819e.

(44) Qiu, P.; Zhu, Y.; Qin, Y.; Shi, X.; Chen, L. Electrical and Thermal Transports of Binary Copper Sulfides Cu x S with x from 1.8 to 1.96. APL 2016, 104805 (May). https://doi.org/10.1063/1.4953439.

(45) Long, S. O. J.; Powell, A. V; Vaqueiro, P.; Hull, S. High Thermoelectric Performance of Bornite through Control of the $\mathrm{Cu}$ (II) Content and Vacancy Concentration. Chem. Mater. 2018, No. Ii. https://doi.org/10.1021/acs.chemmater.7b04436.

(46) Ge, Z.; Chong, X.; Feng, D.; Zhang, Y.; Qiu, Y.; Xie, L.; Guan, P.; Feng, J.; He, J. Achieving an Excellent Thermoelectric Performance in Nanostructured Copper Sul Fi de Bulk via a Fast Doping Strategy. MTP 2019, 8, 71-77. https://doi.org/10.1016/j.mtphys.2019.01.003.

(47) Tang, H.; Zhuang, H.; Cai, B.; Dong, J.; Sun, F.; Li, J. Enhancing the Thermoelectric Performance of $\mathrm{Cu} 1.8 \mathrm{~S}$ by $\mathrm{Sb} / \mathrm{Sn}$ Co-Doping and Incorporating Multiscale Defects to Scatter Heat-Carrying Phonons. JMCC 2019, No. August. https://doi.org/10.1039/c9tc01096c.

(48) Mao, T.; Qiu, P.; Hu, P.; Du, X.; Zhao, K.; Wei, T.; Xiao, J.; Shi, X.; Chen, L. Decoupling Thermoelectric Performance and Stability in Liquid-Like Thermoelectric Materials. AS 2019, 1901598, 1-8. https://doi.org/10.1002/advs.201901598.

(49) Dennler, G.; Chmielowski, R.; Jacob, S.; Capet, F.; Roussel, P.; Zastrow, S.; Nielsch, K.; Opahle, I.; Madsen, G. K. H. Are Binary Copper Sulfides/Selenides Really New and Promising Thermoelectric Materials? Adv. Energy Mater. 2014, 4 (9), 1-12. https://doi.org/10.1002/aenm.201301581.

(50) Zhao, L.; Wang, X.; Fei, F. Y.; Wang, J.; Cheng, Z.; Dou, S.; Wang, J.; Snyder, G. J. High Thermoelectric and Mechanical Performance in Highly Dense Cu2-XS Bulks Prepared by a Melt-Solidification Technique. J. Mater. Chem. A 2015, 3 (18), 94329437. https://doi.org/10.1039/c5ta01667c. 
